OPEN ACCESS

Edited by:

Xu Zhang,

University of Science and Technology

of China, China

Reviewed by:

Ke-Vin Chang

National Taiwan University Hospital,

Taiwan

Wens Hou

Chongqing University, China

*Correspondence:

Qing Wang

wq8740@smu.edu.cn

Wufan Chen

chenwf@smu.edu.cn

Xiaoyun Wang

xiaoyunwang77@hotmail.com

Specialty section:

This article was submitted to

Neurotrauma,

a section of the journal

Frontiers in Neurology

Received: 30 June 2018

Accepted: 24 August 2018

Published: 13 September 2018

Citation:

Wang $Q$, Zhang P, Li P, Song X, Hu H,

Li $X$, Chen W and Wang $X$ (2018)

Ultrasonography Monitoring of

Trauma-Induced Heterotopic

Ossification: Guidance for

Rehabilitation Procedures.

Front. Neurol. 9:771.

doi: 10.3389/fneur.2018.00771

\section{Ultrasonography Monitoring of Trauma-Induced Heterotopic Ossification: Guidance for Rehabilitation Procedures}

\author{
Qing Wang ${ }^{1,3 *}$, Peizhen Zhang ${ }^{1}$, Pengdong $\mathrm{Li}^{2}$, Xiangfen Song ${ }^{1,3}$, Huijing $\mathrm{Hu}^{2}$, Xuan $\mathrm{Li}^{4}$, \\ Wufan Chen ${ }^{1,3 *}$ and Xiaoyun Wang ${ }^{2 *}$ \\ ${ }^{1}$ Department of Biomedical Engineering, Southern Medical University, Guangzhou, China, ${ }^{2}$ Guangdong Work Injury \\ Rehabilitation Center, Guangzhou, China, ${ }^{3}$ Guangdong Provincial Key Laboratory of Medical Image Processing, Southern \\ Medical University, Guangzhou, China, ${ }^{4}$ Nanfang Hospital, Southern Medical University, Guangzhou, China
}

Traumatic injury is one of varying causes of heterotopic ossification (HO). After $\mathrm{HO}$ occurrence, rehabilitation training need alterations to avoid the aggravation of $\mathrm{HO}$. Therefore, monitoring of $\mathrm{HO}$ development plays an important role in the rehabilitation procedure. The aims of this study are to evaluate the post-traumatic $\mathrm{HO}$ occurring at various joints, to describe the features of $\mathrm{HO}$ development in ultrasound images, and to provide a guidance for the orthopedist to make individualized rehabilitation therapy. Eight subjects with the post-traumatic $\mathrm{HO}$ were recruited in this study. The joints on the injured side was examined by plain radiography. The joints on the injured side and the corresponding sites on the uninjured sides were scanned by ultrsonography. The $\mathrm{HO}$ tissues were segmented automatically using a semi-supervised segmentation algorithm. Then the $\mathrm{HO}$ tissues were evaluated in comparison with the corresponding region of the uninjured side. During the development stage of immature $\mathrm{HO}$, ultrasonography was sensitive to observe the involved soft tissue and the calcification of $\mathrm{HO}$. The characteristics of $\mathrm{HO}$ tissues in ultrasound image included the hyperechoic mass occasionally accompanied with acoustic shadow and the irregular muscular architecture. It was found that the mean grayscale value of $\mathrm{HO}$ was significantly higher $(p<0.001)$ than that of the uninjured side at the middle and late stages. During the development period of $\mathrm{HO}$, the $\mathrm{HO}$ grayscale value gradually increased and the mean grayscale of value of mature $\mathrm{HO}$ was significantly higher $(p<0.05)$ than that of immature $\mathrm{HO}$. According to the information of $\mathrm{HO}$ provided by ultrasound, the orthopedist properly adjusted the rehabilitation treatment. The results demonstrated that the visualization of $\mathrm{HO}$ using ultrasonography revealed the development of $\mathrm{HO}$ in the muscle tissues around the injured joints and thus provide a guidance for the orthopedist to make individualized rehabilitation therapy. Ultrasound could be a useful imaging modality for quantitative evaluation of $\mathrm{HO}$ during the rehabilitation of traumatic injury.

Keywords: heterotopic ossification, ultrasonography, trauma, rehabilitation, diagnosis 


\section{INTRODUCTION}

Heterotopic ossification (HO) has been clinically described as lamellar bone formation in the periarticular soft tissues, where osseous tissue should not exist. This aberrant bone formation is commonly associated with orthopedic interventions, trauma, stroke, traumatic brain injury, spinal cord injury, and neurological disorder. Therefore, it is summarized under three ways of acquiring $\mathrm{HO}$ : traumatic, non-traumatic (very rare), or neurogenic. However, the definitive pathogenesis of $\mathrm{HO}$ is still quite unclear. Early $\mathrm{HO}$ causes restriction of joint movement, local pain and swelling. The clinical symptoms of early superficial HO may include erythema and localized warmth $(1,2)$. At the late stage of $\mathrm{HO}$, the mature osseous tissues lead to severe limitation of the range of motion of the joint, pain in the affected joints, and even nerve or vessel compressed by HO (2).

In the clinical laboratory, biochemical markers such as serum alkaline phosphatase (AP) and bone alkaline phosphatase (BAP) are usually examined to reveal the alterations in bone metabolism. The changes in biochemical markers reflect the bone formation or bone resorption, but could not provide visualization of the change of bone (3). Citak et al. proved that laboratory findings of elevated AP and BAP might not be reliable for early $\mathrm{HO}$ detection because of their low diagnostic specificity (4). Therefore, the laboratory examinations are not suggested to be routine examination.

Nowadays, several imaging modalities have been applied to evaluate HO. In department of orthopedics in a hospital, plain radiography is usually used to locate and visualize the heterotopic bone tissues. Plain radiograph is considered as the gold standard of the clinical diagnosis of $\mathrm{HO}$ because it is inexpensive and convenient to detect HO. Computed tomography (CT) is sometimes used to provide 3-D information of $\mathrm{HO}$ and clearly observe the location and volume of HO. However, the cost of CT exam is high. Patients are exposed to a higher dose of radiation by plain radiography and $\mathrm{CT}$, which only provide the diagnosis of $\mathrm{HO}$ in the late stage that the osseous tissues develop into the matured bone. Therefore, these two imaging modalities are unable to detect ossification in the early inflammatory stage. The HO progression needs to be further evaluated (2). Magnetic resonance imaging (MRI) is useful for imaging soft tissue in the early stage of HO. Ledermann et al. proposed a $\mathrm{HO}$ grading scale based on MRI characteristics to evaluate the development of HO: grade 1 = fluid attenuation without calcifications, grade $2=$ calcification of soft tissue without evidence of bone formation, grade $3=$ immature bone formation, and grade $4=$ mature bone with cortical formation (5). However, MRI has low resolution and is expensive and relatively insensitive to the bone tissues.

The advantages of ultrasonography are that ultrasound avoids ionizing radiation, and is widely available, repeatable and inexpensive for bedside monitoring (6). It is proved that ultrasound is a sensitive imaging method in evaluation of soft tissue lesions and calcifications (7). Some previous studies utilized ultrasonography to evaluate the muscle tissues by measurements of grayscale value and thickness of the muscles $(8,9)$. Furthermore, the relationship between ultrasound measurements and the diseases were explored $(8,10)$. A recent study revealed the negative correlation between the echo intensity of the rectus femoris and muscle strength (11). Other previous studies demonstrated that ultrasound could be effective for detecting immature HO. Bedside ultrasound were applied to diagnose immature $\mathrm{HO}$ caused by brain or spinal cord injury and the results suggested that ultrasonography could be a useful first-line imaging modality in the diagnosis of early HO (12-14). Recent studies stated that ultrasonography could distinguish matured $\mathrm{HO}$ from the surrounding soft tissues with a high specificity (15-17). Trauma leading to artificial joint replacement and internal fixation of bone fracture without neurological injury, may also cause $\mathrm{HO}$. The rehabilitation outcome of the injured joints may be greatly affected by HO. Therefore, ultrasonography could be applied in orthopedic rehabilitation for providing a guidance for the orthopedist to make individualized rehabilitation therapy. However, quantitative evaluation of $\mathrm{HO}$ and serial follow-up ultrasonography for depicting $\mathrm{HO}$ progression were rarely reported.

In this study, ultrasonography was applied to observe the calcification in soft tissues in the participants with the posttraumatic $\mathrm{HO}$ caused by trauma such as bone fracture and contusion in the rehabilitation center. The aims of this study are to evaluate the post-traumatic $\mathrm{HO}$ occurring at various joints, to describe the features of $\mathrm{HO}$ development in ultrasound images, and to provide a guidance for the orthopedist to make individualized rehabilitation therapy. The ultrasonographic results were compared with those of plain radiography, which is the gold standard of the clinical diagnosis of $\mathrm{HO}$ in orthopedics.

\section{MATERIALS AND METHODS}

\section{Participants}

The participants were selected from Guangdong Work Injury Rehabilitation Center, China. The criteria of participants include the following: (I) trauma such as fractures, dislocations and contusion occurring at the joints, (II) ossification in soft tissues surrounding the injured joint but not attaching to the cortical bone visualized by radiograph, and (III) motion restriction and pain of the affected joints. Eight participants (6 males and 2 females, Age: 23-48) with symptoms of $\mathrm{HO}$ were recruited. The exclusion criteria include the following: (I) inadequate acquisition of ultrasound images, and (II) osteochondroma. The basic information for the participants is shown in Table 1. Four participants had post-traumatic $\mathrm{HO}$ at the elbow joint (50\%), 3 at knee joint (37.5\%), and 1 at shoulder joint (12.5\%).

The clinical assessments of the range of joint motion were conducted by an experienced physiotherapist. The study was approved by the Ethics Committee of the Guangdong Work Injury Rehabilitation Center, Guangzhou, China. All subjects provided written informed consent prior to enrollment.

\section{Apparatus}

In this study, four participants No. 1, 2, 3, and 4 were scanned by a portable ultrasound system (Mindray M5, Mindray, Shenzhen, China) with a linear transducer (Mindray 7L4s, a range of central 
TABLE 1 | Background data of the participants.

\begin{tabular}{|c|c|c|c|c|}
\hline $\begin{array}{l}\text { Participant } \\
\text { No. }\end{array}$ & $\begin{array}{l}\text { Age } \\
\text { (years) }\end{array}$ & Injured joint & Traumatic injury & Range of joint motion \\
\hline 1 & $30-35$ & Right elbow & $\begin{array}{l}\text { Bone fracture of distal humerus \& head of } \\
\text { radius }\end{array}$ & Extension: $50^{\circ}$; flexion: $85^{\circ}$ \\
\hline 2 & $20-25$ & Left shoulder & Bone fracture of humerus surgical neck & Limited motion range of left shoulder joint \\
\hline 3 & $40-45$ & Left knee & $\begin{array}{l}\text { Splintered bone fracture of patella with } \\
\text { collateral \& cruciate ligament injury }\end{array}$ & Extension: $5^{\circ}$; flexion: $15^{\circ}$ \\
\hline 4 & $44-49$ & Left elbow & $\begin{array}{l}\text { Bone fracture of lateral epicondyle of humerus } \\
\text { with muscle strength reduction }\end{array}$ & Extension: $25^{\circ}$; flexion: $110^{\circ}$ \\
\hline 5 & $45-50$ & Right knee & Soft tissue avulsion \& contusion of proximal end & Flexion: $25^{\circ}$ \\
\hline 6 & $43-48$ & Right elbow & Splintered bone fracture of distal humerus & Extension: $30^{\circ}$; flexion: $40^{\circ}$; adduction: $70^{\circ}$; abduction: $50^{\circ}$ \\
\hline 7 & $40-45$ & Right elbow & $\begin{array}{l}\text { Splintered bone fracture of ulnar coronoid } \\
\text { process \& head of radius }\end{array}$ & Extension: $30^{\circ}$; flexion: $105^{\circ}$; adduction: $10^{\circ}$; abduction: $40^{\circ}$ \\
\hline 8 & $45-50$ & Left knee & Bone fracture of tibial plateau & Extension: $10^{\circ}$; flexion: $55^{\circ}$ \\
\hline
\end{tabular}

frequency from 5 to $10 \mathrm{MHz}$ ). The other four participants No. 5, 6, 7, and 8 were scanned by a wireless ultrasound probe with a fixed central frequency of $10 \mathrm{MHz}$ (Uprobe-3N, linear transducer, SonoStar, Guangzhou, China). A pilot test was conducted to ensure that the B-mode grayscale images obtained by the two ultrasound systems were of similar image quality.

All participants underwent examination of plain radiography (Aristos VX plus, SIEMENS, Germany). Two participants No. 4 and 5 were also examined by CT to obtain more information of the injured joint to distinguish $\mathrm{HO}$ from osteochondroma.

\section{Procedure of Ultrasound Examination}

After examination of plain radiography, all participants were examined by ultrasonography. First, the injured joint was scanned at the site of $\mathrm{HO}$ occurrence (Figure 1). The ultrasound probe was placed on the scan site with enough coupling gel interposed between the transducer and the skin. The depth of view of the ultrasonographic scan was set at $4 \mathrm{~cm}$ for the joints to clearly display the HO lesions and the structure of the muscles and bone. The gain was fixed at a constant intensity for all scans. All the ultrasound images were obtained respectively at the short and long axis of the muscles. Next, the same scanning procedure was performed at the corresponding site on the uninjured side as control.

Because participant No. 8 was with $\mathrm{HO}$ on the immature bone formation stage, he underwent the first ultrasound scan 2 days after the first plain radiography and the follow-up ultrasound scan was performed every week. Four follow-up scans were performed to monitor the development of HO. At each time point, five longitudinal and transverse ultrasound images of $\mathrm{HO}$ were obtained at the adjacent scan sites with an interval of approximately $0.5 \mathrm{~cm}$, respectively. During this period of ultrasound monitoring, the participant was also underwent rehabilitation therapy. At the end of this study, the participant underwent an additional X-ray examination again.

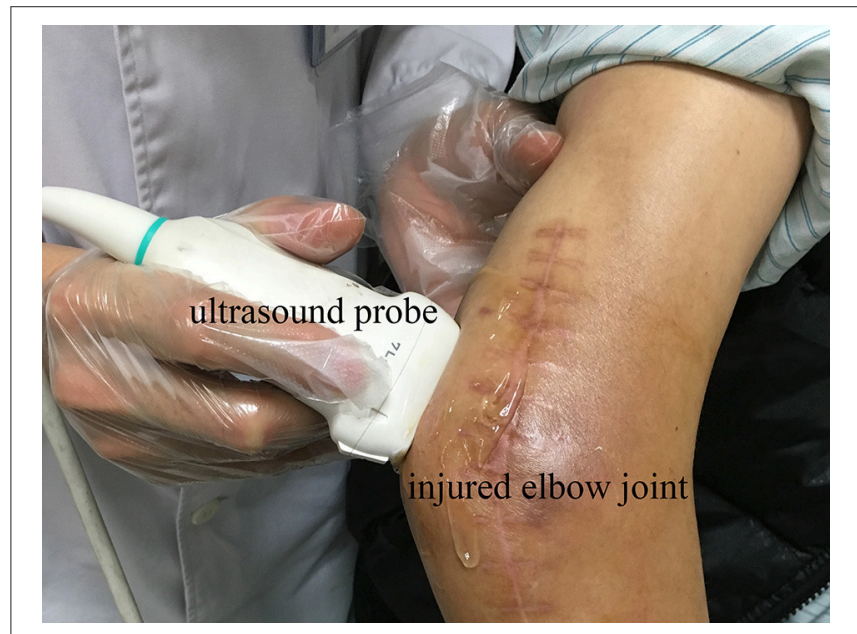

FIGURE 1 | Longitudinal ultrasound scanning of $\mathrm{HO}$ at the posteriorlateral site of the injured elbow joint of participant No. 1.

For the participants with mature $\mathrm{HO}$, the ultrasound scan was performed 2 days after plain radiography without the follow-up ultrasound scan.

\section{Segmentation and Assessment of $\mathrm{HO}$}

Because the edge of the target tissue was not easily distinguished from the background in the ultrasound image, manual segmentation of the $\mathrm{HO}$ tissue was time consuming and operator dependent. Therefore, this study applied a semi-supervised segmentation algorithm based on patch representation and continuous min cut (18) to semi-automatically segment the region of interest (ROI) of $\mathrm{HO}$ in ultrasound image. Under semisupervision of the clinical expertise, the $\mathrm{HO}$ can be accurately and specifically segmented from the surrounding soft tissues according to the texture features of the $\mathrm{HO}$ and muscles. Figure $2 \mathrm{~A}$ shows the HO ROI segmented from the background in ultrasound grayscale images of the injured joint. Meanwhile, a same size ROI of the health tissues was selected at the corresponding position on the uninjured side (Figure 2B). 
After segmentation of the tissues, the ultrasound characteristics of the images were assessed. The mean grayscale values of the $\mathrm{HO}$ tissue was quantitatively evaluated in comparison with the normal muscle tissue.

The segmentation and calculation of mean grayscale value were performed by a self-developed program using Matrix Laboratory (Matlab, version 2016b).

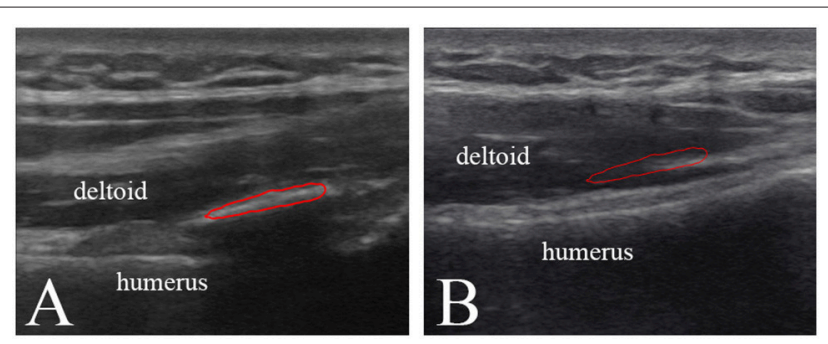

FIGURE 2 | Ultrasound greyscale images of the injured left shoulder joint (A) and the uninjured right shoulder joint (B) of participant No. 2. Red profile in (A) and $\mathbf{B}$ ) represents the $\mathrm{HO}$ segmented from the surrounding soft tissues and the normal muscle tissue selected on the corresponding position, respectively.

\section{Statistical Test}

The results of the pilot study showed that there was no significant difference between the grayscale values of the $\mathrm{HO}$ tissues in ultrasound images recorded using the two ultrasound systems. Therefore, the effect of ultrasound system on the measured grayscale values was not considered in this study.

The grayscale values were expressed as means and standard deviations (mean $\pm \mathrm{SD}$ ). Due to the small number of the participants, the non-parametric statistical tests were utilized in this study. The Mann-Whitney $U$-test was performed to test the statistical significance in the grayscale values between the $\mathrm{HO}$ and health muscle, and Friedman test was performed to test the statistical significance in the grayscale values measured on different time spots during the HO development period. The significance level was set at 0.05 . This statistical analysis was performed by using the Statistical Package of Social Sciences (SPSS, version22, USA).

\section{RESULTS}

The results of plain radiography showed that seven participants were diagnosed with the post-traumatic mature $\mathrm{HO}$ and

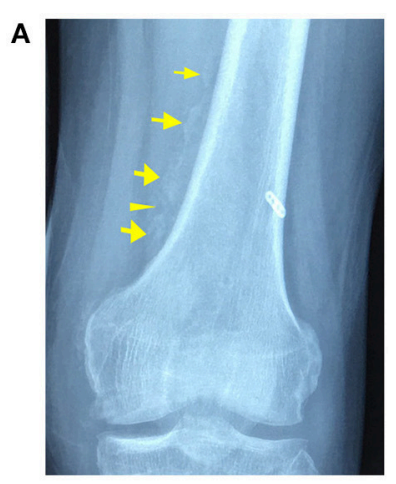

B
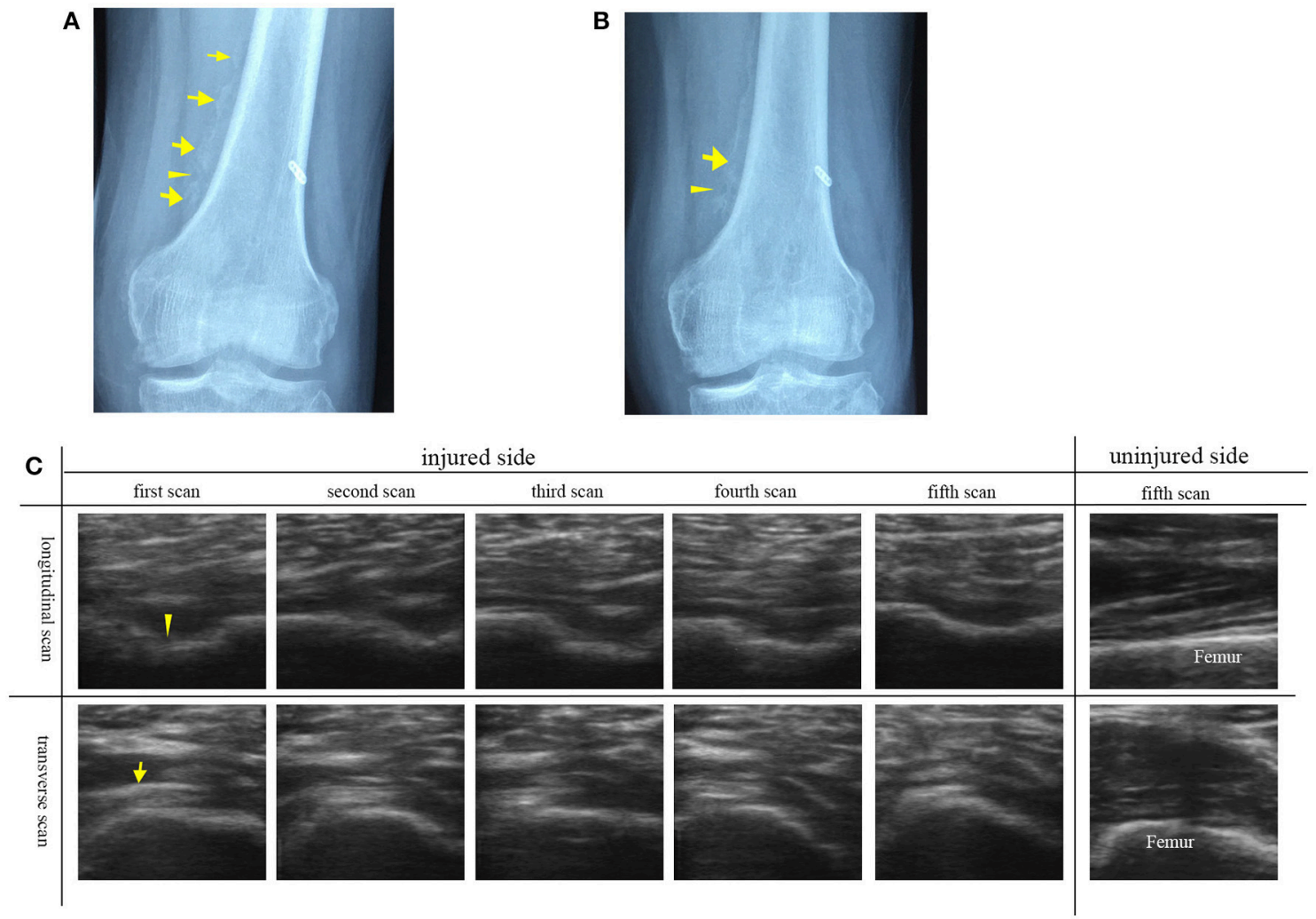

FIGURE 3 | Plain radiographs and ultrasound images of left knee joint of participant No. 8 with HO in the immature bone formation stage. (A) The plain radiograph was taken as the participant was in hospital. Discontinuous (arrowhead), faint and poorly demarcated (arrows) calcification was found. (B) The second plain radiograph was taken $\sim 1$ month after the first plain radiograph. Continuous (arrowhead) and distinguishable (arrow) $\mathrm{HO}$ was found. (C) A series of transverse and longitudinal ultrasound images of the injured joint in comparison with the uninjured side. $\mathrm{HO}$ is visualized during its development. The unconnected $\mathrm{HO}$ tissues (arrowhead) correspond to the gap between two calcified $\mathrm{HO}$ tissues. On the fifth ultrasound images, the $\mathrm{HO}$ tissues connect smoothly to develop into the mature $\mathrm{HO}$ tissues. As the echogenicity and homogenesis of $\mathrm{HO}$ increased, the profile of the femur become blurred (arrow). 
participant No. 8 was with the immature bone formation. Therefore, for participant No. 8, to track the alterations of the immature bone tissue during the development of $\mathrm{HO}$, the followup ultrasound scans and plain radiography were performed.

\section{$\mathrm{HO}$ in the Immature Bone Formation Stage}

The participant No. 8 was in hospital because he suffered swelling and limited range of motion of left knee joint 4 months after surgery for trauma. Figure $\mathbf{3 A}$ shows discontinuous, faint, and poorly demarcated calcification indicating the immaturity of $\mathrm{HO}$. Approximately 1 month after the first plain radiograph, the second plain radiograph showed that the $\mathrm{HO}$ tissues became continuous and distinguishable indicating the more ossified $\mathrm{HO}$ tissues, but still not mature enough for $\mathrm{HO}$ excision (Figure 3B).

In comparison with the plain radiographs, ultrasound images clearly showed the alterations in the anatomic, morphological structure of the involved soft tissues and $\mathrm{HO}$ tissues during the rehabilitation procedure (Figure $3 \mathrm{C}$ ). From the transverse ultrasound images, mixed hyperechoic and hypoechoic areas in the swelling affected muscle tissues and loss of the texture pattern of muscular fibers in the early stage of immature bone formation compared with the health muscle tissues on the uninjured joint. During the development of HO, it was found that the echogenicity and homogenesis of the HO tissues increased as the ossification increased, and an acoustic shadowing caused by the $\mathrm{HO}$ tissues reduced the smoothness of the profile of the femur. Similarily, the longitudinal ultrasound images clearly visualized the development of the immature HO. During rehabilitation procedure, the discontinuous hyperechoic calcified tissues grew to become continuous lamellar $\mathrm{HO}$ tissue (Figure 3C). It was noted that the $\mathrm{HO}$ tissues in ultrasound image (Figure 3C) was consistent with lamellar bone in plain radiograph (Figures 3A,B). Ultrasonography is more sensitive to visualize the involved soft tissue and immature bone formation.

\section{$\mathrm{HO}$ in the Mature Bone Formation Stage}

The ultrasound images of the injured joints show the irregular muscular architecture and the calcified foci (HO) (Figure 4). As Figure 4C shown, irregular hyperechoic areas and loss of deep fascia or aponeruroses in the swelling affected muscles were found in three participants No. 1, 5, and 8. Besides HO tissues, loss of the textural structure of the muscular fibers in the swelling affected muscles was found in participant No. 4 (Figure 4E). Figure 4G shows local muscle evagination due to the $\mathrm{HO}$ tissues in the muscles disturbing the muscle structure and causing worse pain in participant No. 6. With less injured muscles in two participates No. 2 and 3 , the effect of the mature $\mathrm{HO}$ tissues on the texture of muscular fibers sometimes was not obvious (Figure 4A). The characteristics of mature $\mathrm{HO}$ in ultrasound image might include small calcified foci in size but with high echogenicity and sometimes with acoustic shadow. Figures 4B,D,F,H show the normal textural structure and echogenicity of the muscles and bones.

\section{Analysis of Grayscale Value}

Figure 5A shows that at the middle stage of the in immature bone formation the grayscale value $(86.40 \pm 13.42)$ of the immature $\mathrm{HO}$ already increased significantly $(p<0.001)$ compared with the health muscle tissue $(55.1 \pm 12.01)$. At the late stage of $\mathrm{HO}$, it was found that the grayscale value of the mature HO increased greatly (119.09 \pm 22.70$)$ and was significantly higher $(p<0.001)$ than that of to the health soft tissues $(70.06 \pm 31.09)$.
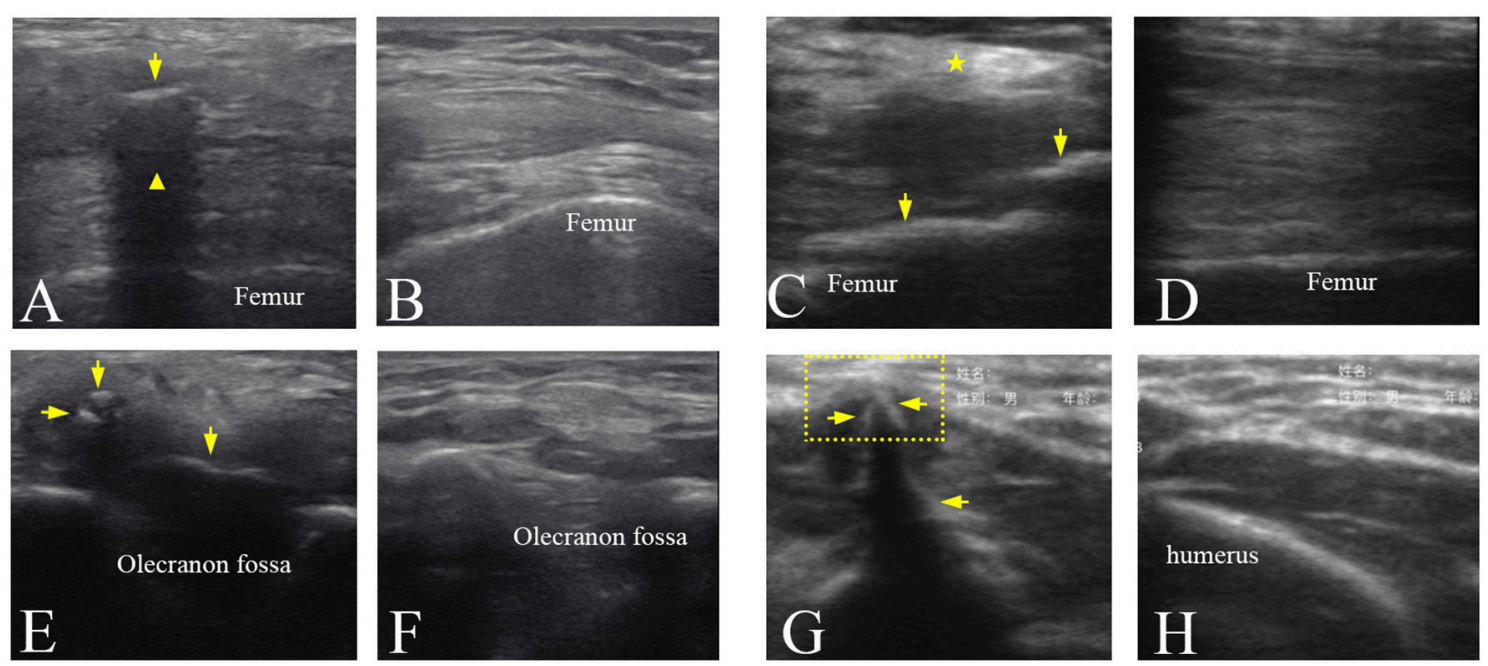

FIGURE 4 | Ultrasound images of the mature $\mathrm{HO}$ in the different joints. (A) Ultrasound image of the left knee joint of participant No. 3 showing that HO (arrow) with an acoustic shadowing $(\mathbf{A})$. (C) Ultrasound image of the right knee joint of participant No. 5 showing a hyperechoic area ( $\downarrow$ ) in the muscles and the $\mathrm{HO}$ tissues (arrows). (E) Ultrasound image of the right elbow joint of participant No. 4 showing the hypoechoic HO tissues (arrows) and loss of the textural structure of muscular fibers. (G) Ultrasound image of the right elbow joint of participant No. 6 showing local muscle evagination (dotted line box) by the hyperechoic HO tissues (arrows). (B,D,F,H) Ultrasound images of corresponding position of the uninjured side in $\mathbf{( A , C , E , G ) , ~ r e s p e c t i v e l y . ~}$ 


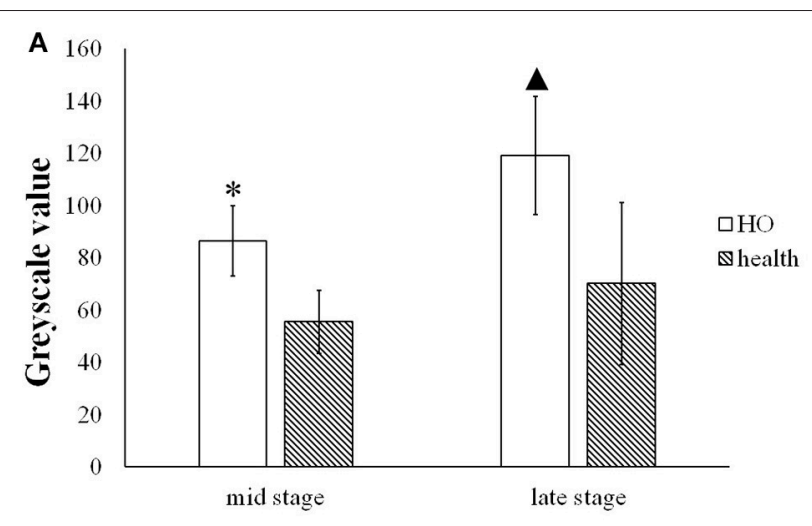

B

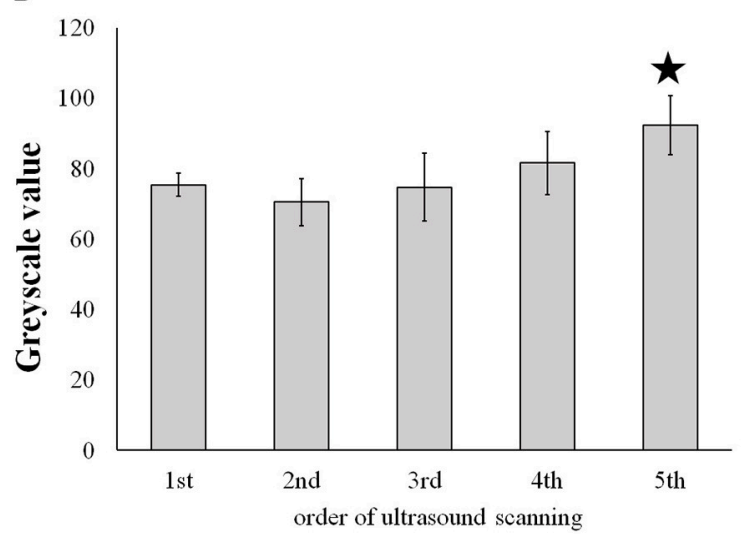

FIGURE 5 | (A) Comparison of the greyscale value of the $\mathrm{HO}$ tissues and the health muscle tissues at the middle and late stage. * and $\mathbf{\Delta}$ present the statistically significant difference between $\mathrm{HO}$ and health muscle $(p<0.001)$. (B) Comparison of the grayscale value of $\mathrm{HO}$ measured on five time spots during the development of $\mathrm{HO}$. $\star$ indicates statistically significant increase in the grayscale value of the 5 th scan v.s. the former four scans $(p<0.05)$.

Figure 5B shows that the gradual increase in the grayscale value of the immature $\mathrm{HO}$ tissues during the development period. The grayscale value of the mature $\mathrm{HO}$ for 5 th ultrasound scan $(92.18 \pm 8.37)$ was significantly increased in comparison with the 1st, $2 \mathrm{nd}, 3 \mathrm{rd}$, and 4 th scans $(p<0.05)$.

\section{Effect of HO on Rehabilitation Therapy}

For the patients with high HO maturity, the strength of the rehabilitation therapy needs to be strengthened appropriately, in order to improve the joint movement function. However, for the patients with low $\mathrm{HO}$ maturity, the strength of rehabilitation treatments such as joint loosening and drafting should be soft in order to avoid locally strained muscles and other soft tissues, which might lead to $\mathrm{HO}$ worsened.

According to the ultrasound images, the orthopedist obtained the information of $\mathrm{HO}$ development of participant No.8. The individualized rehabilitation therapy was performed. The treatment intensity of the traditional rehabilitation training reduced. The participant was anesthetized and underwent with manipulation and arthroscopic surgery. After $\sim 1$-month rehabilitation therapy, the range of extension of the injured knee joint was 5-10, while the range of flexion increased $40^{\circ}$ reaching up to $95^{\circ}$. The muscle strength also slightly increased from grade 4 to grade $4+$. Furthermore, with the increase in maturity of $\mathrm{HO}$, no obvious increase of $\mathrm{HO}$ size was observed via ultrasonography and plain radiography examinations.

\section{DISCUSSION}

\section{HO Muscle and its Neuromuscular Function}

Although the exact mechanism of $\mathrm{HO}$ in traumatic and neurogenic $\mathrm{HO}$ is unknown, two common factors precede the formation of $\mathrm{HO}$ (19). One factor is trauma or neurological injury. The other is the tissue expression of bone morphogenetic proteins (BMPs), which induce bone formation. In this study, all the participants sustained bone fracture at different joints with HO. We found that the morphologic and textural pattern of $\mathrm{HO}$ muscle changed in comparison with normal muscle. Differently, a recent study on spastic muscle induced by spinal cord injury did not find obvious changes in textural pattern of the involved muscle but only shortening of muscle fibers in ultrasound image (20). This may suggest that ultrasonography visualizing the damage in the textural pattern of the involved muscle is able to diagnose $\mathrm{HO}$ tissue.

Further, previous study reported that $\mathrm{HO}$ formation was related to a series of changes within not only muscles but also nerves and vessels (21). Those alterations may affect the neuromuscular function. After traumatic injury, the sensory nerves detect any damage to the bone, for example, the alterations due to trauma and BMPs. Then, the sensory nerves signal to the central nervous system to start the remodeling program. However, new bone is generated in incorrect places, and $\mathrm{HO}$ occurs. Therefore, the regulation of peripheral nerves system is involved in the formation of $\mathrm{HO}(21,22)$.

\section{Quantitative Assessment of Grayscale Value}

Ultrasound images show characteristics, such as size and morphological structure, of the HO tissues. However, these characteristics are individually different in the different joints of different patients. Ultrasound echoes reflect the acoustic impedance, density, stiffness of the tissues. The magnitudes of the echoes are displayed in ultrasound image by grayscale values. During occurrence of HO, primitive mesenchymal cells transform into osteoblasts in the late stage. Previous studies demonstrated that the alterations in the properties of the tissues led to the changes in the ultrasound echoes reflecting the relative diseases (8-11). Therefore, this study chose grayscale value as quantitative parameter, which is relative to the maturity degree of the HO tissues (23). The results show the significant difference in grayscale values not only between the $\mathrm{HO}$ tissue and the health muscle tissue but also between immature and mature $\mathrm{HO}$ tissues. 

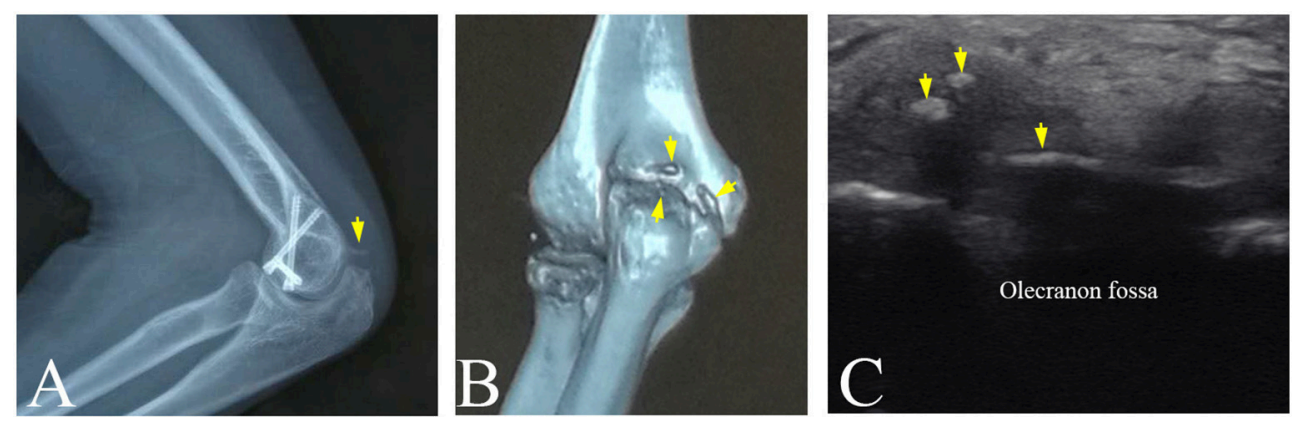

FIGURE 6 | The $\mathrm{HO}$ tissues at left elbow joint of participant No. 4 visualized by multi-modality imaging. (A) A spiny HO (arrow) in plain radiograph. (B) A slender $\mathrm{HO}$ and two small and granular HOs discovered in CT image (arrows). (C) Two small hyperechoic masses and a slender hyperechoic region (arrows) in triceps brachii in ultrasound image.

\section{Radiographic Classification and Evaluation for $\mathrm{HO}$}

Previous studies evaluated and classified HO according to the plain radiograph. Based on radiographic findings, $\mathrm{HO}$ in the hip joint is grouped into four classes (Class I to Class IV), called as the Brooker classification (24). The Hastings and Graham classification system (25) was proposed to evaluate $\mathrm{HO}$ at the elbow joint into three classes. However, these classification systems were only applied to individual joint and did not obtain good classification results of $\mathrm{HO}$ in other anatomical locations.

A recent study proposed an analog scoring method (26) for radiographic classification and evaluation of $\mathrm{HO}$ based on normotopic reference bone. Its results showed high correlation $\left(R^{2}=0.89\right)$ between the scores of the analog scale and the heterotopic bone volumes measured by micro-CT, i.e., higher score means larger size of HO. In comparison with the analog method, this study evaluated grayscale value of $\mathrm{HO}$ in ultrasound image, indicating that higher echogenicity means more mature HO.

\section{Limitation of Plain Radiography}

In department of orthopedics in a hospital, plain radiography is considered as the gold standard of the clinical diagnosis of HO because of its convenience to detect the calcified tissues. However, plain radiography is a method of projection imaging producing two-dimensional images with $\mathrm{x}$-ray radiation through the body tissues. Therefore, the plain radiograph does not provide any depth information. This limitation leads to misjudgment on HO. In this study, participant No.4 suffered from pain and limited range of motion in the left elbow joint. The radiography revealed a lamellated and slender calcification that intersected the distal humerus (Figure 6A). However, 3-D CT image visualized a slender $\mathrm{HO}$ and two small and granular $\mathrm{HO}$ tissues (Figure 6B). Similarily, ultrasonography also displayed two small hyperechoic calcified foci and a lameller hyperechoic region in triceps brachii (Figure 6C). It was found that the overlap of the $\mathrm{HO}$ tissues and distal humerus or other tissues in the radiograph might cause the misdiagnosis of the HO. Other previous studies slimilarily demonstrated that 3-D CT image help plain radiograph accurately locate the position and number of the HO tissues $(27,28)$.

\section{Advantages and Limitations of Ultrasonography in Detection of HO}

Previous studies have proven that ultrasound is a useful tool and provides an earlier diagnosis of neurogenic $\mathrm{HO}$ than radiography (12-14). This study similarily showed that ultrasonography could depict the changes of related soft tissues and immature $\mathrm{HO}$ tissues, that plain radiograph might fail to imagine in orthopedic rehabilitation. The hypoechoic area and loss of the lamellar pattern of muscular fibers in ultrasound image (Figure 4E) probably due to the inflammatory edema surrounding $\mathrm{HO}$. Hyperechoic holistic muscle, especially hyperechoic muscular fibers (Figure 4C) might be caused by the lack of exercise or amyotrophy.

In addition, ultrasonography could be conveniently performed a bedside monitoring using portable or wireless ultrasound device. There was no significant difference between two devices for imaging and quantitatively evaluation of $\mathrm{HO}$. This study demonstrates that grayscale value analysis method for evaluating $\mathrm{HO}$ is independent on ultrasound system. Finally, ultrasonography is suitable for follow-up tracking the development of $\mathrm{HO}$ due to its real-time imaging and no radiation.

However, operator dependency limits the use of ultrasonography (29), especially in department of orthopedics. Most orthopedists themselves have no experiences of performing ultrasound scanning and diagnosing $\mathrm{HO}$ using ultrasound image. And orthopedists are lack of the cooperation with ultrasound specialist. Another limitation of this study is the number of the proper participants. No participant with early stage of post-traumatic HO was included in this study, only one participant with the immature $\mathrm{HO}$ in the middle stage was involved.

\section{CONCLUSION}

In this study, ultrasonography was applied to visualize the development of immature $\mathrm{HO}$ and surrounding soft tissues. 
After the $\mathrm{HO}$ extracted from the ultrasound images, the grayscale value was used to quantitatively assess the immature and mature $\mathrm{HO}$ tissues in the middle and late stage. The results show the significant difference in grayscale values not only between the $\mathrm{HO}$ tissue and the health muscle tissue but also between immature and mature $\mathrm{HO}$ tissues. This study suggested that ultrasonography has potentials to be a useful imaging modality for monitoring the development of $\mathrm{HO}$ and providing quantitative evaluation on HO. Combination of ultrasonography and plain radiography in diagnosis of HO help orthopedists to make individualized rehabilitation therapy.

\section{AUTHOR CONTRIBUTIONS}

QW and XW conceived and designed the study. PZ and PL performed the experiments. QW and PZ wrote the paper. XS, XL,

\section{REFERENCES}

1. Balboni TA, Gobezie R, Mamon HJ. Heterotopic ossification: pathophysiology, clinical features, and the role of radiotherapy for prophylaxis. Int J Radiat. Oncol Biol Phys. (2006) 65:1289-99. doi: 10.1016/j.ijrobp.2006.03.053

2. Vanden Bossche L, Vanderstraeten G. Heterotopic ossification: a review. J Rehabil Med. (2005) 37:129-36. doi: 10.1080/16501970510 027628

3. Delmas PD. Biochemical markers of bone turnover. J Bone Miner Res. (1993) 8(Suppl. 2):S549-55. doi: 10.3109/17453679509 157687

4. Citak M, Grasmucke D, Suero EM, Cruciger O, Meindl R, Schildhauer TA, et al. The roles of serum alkaline and bone alkaline phosphatase levels in predicting heterotopic ossification following spinal cord injury. Spinal Cord (2015) 54:368-70. doi: 10.1038/sc.2015.211

5. Ledermann HP, Schweitzer ME, Morrison WB. Pelvic heterotopic ossification: MR imaging characteristics. Radiology (2002) 222:189-95. doi: 10.1148/radiol.2221010552

6. Ekiz T, Yildizgören MT, Yetişgin A. Musculoskeletal ultrasonography bypasses the diagnostic and radiological challenges in heterotopic ossifcation. Singapore Med J. (2014) 55:604. doi: 10.11622/smedj. 2014161

7. Özçakar L, Kara M, Chang KV, Çarl AB, Akkaya N, Tok F, et al. Nineteen reasons why physiatrists should do musculoskeletal ultrasound: EURO-MUSCULUS/USPRM Recommendations. Am J Phys Med Rehabil. (2015) 94:e45-9. doi: 10.1097/PHM.000000000 0000223

8. Chang KV, Wu WT, Huang KC, Jan WH, Han DS. Limb muscle quality and quantity in elderly adults with dynapenia but not sarcopenia: an ultrasound imaging study. Exp Gerontol. (2018) 108:54-61. doi: 10.1016/j.exger.2018.03.019

9. Pillen S, Tak RO, Zwarts MJ, Lammens MM, Verrijp KN, Arts IM, et al. Skeletal muscle ultrasound: correlation between fibrous tissue and echo intensity. Ultrasound Med Biol. (2009) 35:443-6. doi: 10.1016/j.ultrasmedbio.2008.09.016

10. Chang KV, Chen WS, Wang TG, Hung CY, Chien KL. Quantitative ultrasound facilitates the exploration of morphological association of the long head biceps tendon with supraspinatus tendon full thickness tear. PLoS ONE (2014) 9:e113803. doi: 10.1371/journal.pone.0113803

11. Mota JA, Giuliani HK, Gerstner GR, Ryan ED. The rate of velocity development associates with muscle echo intensity, but not muscle crosssectional area in older men. Aging Clin Exp Res. (2018) 30:861-5. doi: 10.1007/s40520-017-0829-1 and $\mathrm{HH}$ contributed to experiments. XW and WC reviewed and edited the manuscript. All authors had read and approved the manuscript.

\section{FUNDING}

This work was supported in part by the Project of Science and Technology Department of Guangdong province (No. 2016A020216017 and No. 2013B021800039), the National Natural Science Foundation of China (No. 81371560), and Natural Science Foundation of Guangdong Province, China (No. 2014A030313329, No. 2015A0303 10527).

\section{ACKNOWLEDGMENTS}

The authors would like to thank all the participants of this study.

12. Falsetti P, Acciai C, Palilla R, Carpinteri F, Patrizio C, Lenzi L. Bedside ultrasound in early diagnosis of neurogenic heterotopic ossification in patients with acquired brain injury. Clin Neurol Neurosur. (2011) 113:22-7. doi: 10.1016/j.clineuro.2010. 08.012

13. Rosteius T, Suero EM, Grasmucke D, Aach M, Gisevius A, Ohlmeier M, et al. The sensitivity of ultrasound screening examination in detecting heterotopic ossification following spinal cord injury. Spinal Cord (2017) 55:71-3. doi: 10.1038/sc.2016.93

14. Stefanidis K, Brindley P, Ramnarine R, Blaivas M, Daneshi M, Sidhu PS, et al. Bedside ultrasound to facilitate early diagnosis and ease of follow-up in neurogenic heterotopic ossification: a pilot study from the intensive care unit. J. Head Trauma Rehabil. (2017) 32:E54-8. doi: 10.1097/HTR.0000000000000293

15. Kara M, Ekiz T, Öztürk GT, Onat SS, Özçakar L. Heterotopic ossifcation and peripheral nerve entrapment: ultrasound is a Mustuse imaging modality. Pain Med. (2015) 16:1643-44. doi: 10.1111/pme. 12749

16. Kara M, Yalçin S, Yenigün D, Tiftik T, Malas FÜ, Özçakar L. Heterotopic ossifcation and cubital tunnel syndrome in traumatic brain injury: Ultrasound 'sees' both. J Back Musculoskelet Rehabil. (2015) 28:415-17. doi: 10.3233/BMR-140519

17. Onat SS, Özişle Z, Orhan A, Akman B, Köklü K, Özçakar L. Ultrasonographic diagnosis of heterotopic ossifcation and secondary nerve entrapments in a patient with spinal cord injury. Med Ultrason. (2017) 19:336-40. doi: $10.11152 / \mathrm{mu}-1121$

18. Ciurte A, Bresson X, Cuisenaire O, Houhou N, Nedevschi S, Thiran JP, et al. Semi-supervised segmentation of ultrasound images based on patch representation and continuous min cut. PLoS ONE (2014) 9:e100972. doi: 10.1371/journal.pone.0100972

19. Sun E, Hanyu-Deutmeyer AA. Heterotopic Ossification. StatPearls [Internet]. Treasure Island (FL): StatPearls Publishing; (2018).

20. Jiang L, Wang YJ, Wang QY, Wang Q, Wei XM, Li N, et al. Correlation between pathological characteristics and young's modulus value of spastic gastrocnemius in a spinal cord injury rat model. Biomed Res Int. (2017) 2017:5387948. doi: 10.1155/2017/5387948.

21. Salisbury E, Sonnet C, Heggeness M, Davis AR, Olmsted-Davis E. Heterotopic ossification has some nerve. Crit Rev Eukaryot Gene Expr. (2010) 20:313-24.

22. Gugala Z, Olmsted-Davis EA, Xiong Y, Davis EL, Davis AR. Trauma-induced heterotopic ossification regulates the blood-nerve barrier. Front Neurol. (2018) 5:408. doi: 10.3389/fneur.2018.00408

23. AI Mukaddam M, Rajapakse CS, Pignolo RJ, Kaplan FS, Smith SE. Imaging assessment of fibrodysplasia ossificans progressiva: qualitative, quantitative 
and questionable, Bone (2018) 109:147-52. doi: 10.1016/j.bone.2017. 08.011

24. Brooker AF, Bowerman JW, Robinson RA, Riley LH Jr. Ectopic ossification following total hip replacement. Incidence and a method of classification. $J$ Bone Joint Surg Am. (1973) 55:1629-32.

25. Hastings H II, Graham TJ. The classification and treatment of heterotopic ossification about the elbow and forearm. Hand Clin. (1994) 10:417-37.

26. Rajapakse CS, Lindborg C, Wang H, Newman BT, Kobe EA, Chang G, et al. Analog method for radiographic assessment of heterotopic bone in fibrodysplasia ossificans progressive. Acad Radiol. (2017) 24:321-7. doi: 10.1016/j.acra.2016. 10.010

27. Cipriano CA, Pill SG, Keenan MA. Heterotopic ossification following traumatic brain injury and spinal cord injury. J Am Acad Orthop Surg. (2009) 17:689-97.

28. Arduini M, Mancini F, Farsetti P, Piperno A, Ippolito E. A new classification of peri-articular heterotopic ossification of the hip associated with neurological injury. Bone Joint J. (2015) 97-B:899-904. doi: 10.1302/0301-620X.97B7. 35031

29. Ranganathan K, Hong X, Cholok D, Habbouche J, Priest C, Breuler C, et al. High-frequency spectral ultrasound imaging (SUSI) visualizes early posttraumatic heterotopic ossification (HO) in a mouse model. Bones (2018) 109:49-55. doi: 10.1016/j.bone.2018.01.034

Conflict of Interest Statement: The authors declare that the research was conducted in the absence of any commercial or financial relationships that could be construed as a potential conflict of interest.

Copyright (C) 2018 Wang, Zhang, Li, Song, Hu, Li, Chen and Wang. This is an open-access article distributed under the terms of the Creative Commons Attribution License (CC BY). The use, distribution or reproduction in other forums is permitted, provided the original author(s) and the copyright owner(s) are credited and that the original publication in this journal is cited, in accordance with accepted academic practice. No use, distribution or reproduction is permitted which does not comply with these terms. 